\title{
RELAÇÃO ENTRE CONFIABILIDADE DAS NOTÍCIAS E ALTURA DE VOZ DE REPÓRTERES DO JN, SBT BRASIL E JR
}

\author{
Maria Imaculada Pereira Azeredo* \\ Vera Pacheco ${ }^{* *}$
}

RESUMO: Esta pesquisa traz a seguinte questão: existe uma relação entre confiabilidade da matéria jornalística e altura de vOZ de repórteres? Nossa hipótese é a de que não existe mais uma relação intrínseca entre a altura da voz e a confiabilidade da matéria. Nosso objetivo é investigar se a confiabilidade de uma matéria está relacionada à altura da vOz do telejornalista. Para isso, selecionamos vídeos de matérias telejornalísticas transmitidas no ano de 2017 e os exibimos para um público alvo para que julgassem a confiabilidade das matérias e a altura das vozes dos repórteres. Os resultados encontrados ratificam nossa hipótese de que não existe uma relação intrínseca entre altura de voz e confiabilidade.

PALAVRAS-CHAVE: Confiabilidade; Altura de voz; Repórteres; Matérias; Público.

\section{Introdução}

O senso comum aponta para uma ideia geral de que para se falar bem, ser agradável, passar confiabilidade e credibilidade nas produções jornalísticas de jornais tradicionais é preciso impostar a voz num tom grave. Talvez esta ideia advenha dos primeiros anos do telejornalismo, em que, conforme explica Reiniger (2004), a narração, inspirada no rádio e no jornal impresso, adotou um estilo de voz impostada e dura.

Sem o objetivo de entrar nesta discussão, assumimos o pressuposto do qual a ideia de que a bela voz seja a voz grave, venha da tradição do rádio. De acordo com Vigil (1997, p. 75$)$,

o rádio começou a fazer a cotação das vozes elegantes, redondas, completas. Vozes profundas para os homens, cristalinas para as mulheres. Quem não arrancasse um trovão da goela, não servia para locutor. Quem não exibisse um rouxinol na garganta, não servia para locutora.

\footnotetext{
* Mestre em Linguística pela Universidade Estadual do Sudoeste da Bahia (Uesb).

** Doutora em Linguística pela Universidade Estadual de Campinas (Unicamp). Professora Plena da Universidade Estadual do Sudoeste da Bahia (Uesb).
} 
Conforme narram Kyrillos (2003) e Guimarães (2007) (apud PORTINHA, 2011, p. 87), os primeiros apresentadores e repórteres de televisão vinham do rádio, trazendo consigo um padrão de voz imposta, com enfoque nos tons graves, loudness ${ }^{1}$ forte e sobrearticulação $^{2}$. Essas afirmativas nos fazem crer que a ideia da voz grave e impostada venha justamente daí e, a partir disto, também surgiu a ideia de que a credibilidade e a confiabilidade dos repórteres estavam relacionadas ao tom grave da voz.

A partir desses pressupostos, levantamos a seguinte pergunta: existe uma relação entre a confiabilidade da matéria jornalística e a altura de voz de repórteres? Nossa hipótese é a de que não existe mais uma relação intrínseca entre a altura da voz e a confiabilidade da matéria. No entanto, acreditamos que ainda seja preferível o tom mais grave ao tom mais agudo. Assim, nosso objetivo neste trabalho é investigar se a confiabilidade de uma matéria está relacionada à altura da vOz do telejornalista.

\section{Confiabilidade e credibilidade jornalística}

De acordo com alguns dicionários da Língua Portuguesa ${ }^{3}$, credibilidade é a qualidade daquilo que é crível. Russi (2016, p. 71) explica que a credibilidade "é um fator construído pelo ser social para dotar algo ou alguém de um poder de crença, de ser crível, capacitando-o a ser confiável perante ao indivíduo ou ao grupo.” Já confiabilidade, de acordo com os dicionários, é a qualidade do que é confiável, que inspira confiança, que não provoca dúvidas. Belda e Santos (2017, p. 3-4), comentam os dois conceitos e afirmam que eles - credibilidade e confiabilidade - não devem ser confundidos. Para os autores:

A credibilidade, como aponta Serra (2006b), é um atributo construído através de uma relação entre o produtor/emissor da informação e o receptor. É uma qualidade atribuída ao orador, instituição

\footnotetext{
1 Também conhecida como intensidade.

2 A técnica de sobrearticulação consiste em exagerar os movimentos fonoarticulatórios, fazendo ampla excursão muscular, com grande abertura de boca e emitindo cada sílaba com precisão excessiva, com grande tonicidade laríngea ou da cintura escapular. Disponível em: < https://www.portaleducacao.com.br/conteudo/artigos/educacao/orientacoes-para-o-paciente/16321> Acesso em: 16, Dezembro, 2017.

${ }^{3}$ Fontes: Dicio. Disponível em: https://www.dicio.com.br/; Dicionário Aurélio. Disponível em: https://dicionariodoaurelio.com/; Dicionário Priberam. Disponível em: < https://www.priberam.pt/>.
} 
ou discurso a partir do momento que o discurso se prova, através de suas características - no caso seguindo os preceitos jornalísticos -, credível. Mas não apenas: um discurso pode ser visto como credível a partir da credibilidade atribuída a seu emissor, em funções de qualidades do enunciador, mesmo que ausentes do enunciado. [...] Já a confiança, define Rousseau (1998 apud Lewicki e Tomlinson, 2003, p.1), é "um estado psicológico que compreende a intenção de aceitar a vulnerabilidade baseado em expectativas positivas das intenções ou do comportamento do outro" (grifo nosso).

Desse modo, as noções de confiabilidade e credibilidade compreendem elementos tanto quanto subjetivos. Notemos que os autores explicam que a credibilidade está relacionada tanto à qualidade do discurso, quanto à relação jornalista/ouvinte, já a confiança está relacionada ao recebimento e aceitação do público em relação à matéria. Quem define se um discurso é de qualidade, se o jornalista é credível e se o que se é transmitido é aceitável, é o telespectador. Um jornalista pode ser confiável para um sujeito e pode não passar confiança para outro. Russi (2016, p. 69) ainda explica que "o indivíduo realiza uma avaliação do quanto o locutor ou a mensagem recebida é confiável para, então, aceitá-la como verdadeira". Então esse processo de avaliação e aceitação é pessoal e vai de acordo com o que cada um acredita ser bom ou não.

Batista e Figueiredo (2010, p. 2) afirmam que "a fidelidade da comunicação depende dos padrões de articulação, pronúncia e impostação vocal, visto que a credibilidade é, em grande parte, garantida pela expressividade vocal".

Panico e Fukusima (2003) afirmam que para que se transmita confiabilidade, o jornalista deve apresentar um ritmo dinâmico e natural a fala. Além de os homens buscarem por um "tom mais grave dentro de sua possibilidade de produção" (PANICO; FUKUSIMA, 2003, p. 57). Já as vozes femininas, mesmo agudas, de acordo com os autores, é apontada como confiável.

Segundo Silva e Castro (2003, apud BATISTA; FIGUEIREDO, 2010), ao noticiar um fato, o jornalista deve garantir que a informação seja entendida tanto pelo agricultor, quanto pelo intelectual. Dessa forma, o jornalista, além de ter um bom texto, também 
precisa ter um padrão vocal estável e expressivo para oferecer credibilidade à matéria e obter a confiança de seus telespectadores.

Senese (2008, p. 47), embasado em Kyrillos (2003), afirma que

o uso adequado da voz no telejornalismo é fundamental [...], pois a imagem representada e o papel que o repórter desempenha no vídeo são fatores que refletem na efetiva comunicação do conteúdo da notícia, cujo maior desafio é fazer com que a mensagem seja recebida pelo público com credibilidade. O profissional precisa ter domínio dos elementos verbais, como voz agradável, articulação clara, ritmo de fala, modulação, bom texto, adequada seleção vocabular e ordenação gramatical, bem como dos elementos não-verbais, como expressão corporal, facial e gestual.

Assim, para se passar credibilidade e conquistar a confiança do público, o jornalista, além de ter um bom texto, precisa saber falar esse texto, ou, como bem afirma Cunha (1998), “interpretar o texto”. Para o autor (1998), “o tom de voz deve ser colocado de forma coerente. As pausas devem ser intencionais, em seu tempo justo. As variações (entonações) internas no clima do texto reveladas sempre" (CUNHA, 1998, p. 51). Apenas deste modo, o jornalista obterá aquilo que deseja, que é justamente a confiança e a audiência do público.

\section{A importância da voz nos telejornais}

Cagliari (2007, p. 127) explica que a "voz de um homem se distingue da voz de uma mulher [...] porque eles têm aparelhos fonadores com dimensões absolutas diferentes". Comumente, mulheres têm vozes mais agudas, comparando as vozes masculinas, conforme indica Pacheco (2006). Inversamente, Cagliari $(1997,2007)$ e Pacheco (2006) explicam que os homens têm vozes mais graves se comparadas às vozes de mulheres e crianças.

De acordo com os estudos de Pacheco (2006, p. 51), normalmente "os homens, na fala diária, possuem uma variação de frequência fundamental típica, que gira em torno de 80 e $200 \mathrm{~Hz}$; as mulheres entre 180 e $400 \mathrm{~Hz}$ ". E é justamente por ter a frequência fundamental mais baixa que a das mulheres, que os homens comumente têm a voz mais grave e as mulheres, mais agudas. 
Maia (2003) explica que a fala é um som e o som é composto por ondas sonoras que têm a forma de senóide. Malmberg (1954) esclarece que quanto maior o ciclo de uma senóide, menor será a frequência da onda, dessa forma, mais grave será o som. Inversamente, quanto menor o ciclo de uma senóide, maior será a frequência, configurando, então, um som mais agudo.

Então, de forma sucinta, a frequência fundamental (F0) é um parâmetro acústico que está relacionado ao número de vezes que as pregas vocais vibram por segundo, produzindo, assim, perceptualmente, uma voz mais grave ou mais aguda. Quanto mais vibrações, mais agudo é o som e quanto menos vibrações, mais grave o som será. Daí percebemos que, por possuir frequências fundamentais mais baixas que as mulheres, os homens tendem a ter uma voz mais grave e as mulheres, mais aguda.

No início do telejornalismo brasileiro (ainda na década de 1950), os jornalistas seguiam uma tendência ao agravamento da voz, a fim de "formalizar" o falar, de acordo com Cotes (2008). Contudo, a autora ainda observa que gradativamente os jornalistas foram abandonando o estilo formal e naturalizando a sua fala. É certo que o cuidado com a impostação da voz ainda existe, no entanto, o padrão "Cid Moreira" ${ }^{4}$ " de voz está perdendo espaço dentro dos telejornais. O formal está saindo de cena para dar espaço ao cotidiano, ao diálogo quase informal.

Hoje é comum nos telejornais, mesmo os regionais, a inserção das telas interativas, que permitem que o âncora se levante da bancada para interagir e "conversar" com um repórter que apareça nelas num momento de "ao vivo". Isso gera a sensação de descontração, na qual o âncora vira de lado como se dialogasse, frente a frente, com o repórter (o que, de fato, sabemos que não acontece, já que o repórter está voltado para uma câmera e não para o âncora no estúdio). Também pode ocorrer de o âncora de um telejornal conversar com outro setor da emissora ou com um jornal regional que esteja sendo transmitido no mesmo horário. No Bom Dia Brasil, por exemplo, essa é uma prática muito comum 
(quase diariamente os âncoras do programa conversam com o âncora de um telejornal regional).

Cunha (1990, p. 51) explica que o "locutor perfeito não tem sotaque carregado." Ele precisa compreender o texto, interpretar o que ele significa e, então, determinar qual o melhor tom para aquela notícia. O autor complementa ainda:

O comunicador ao proferir sílabas ou palavras, dependendo da pronúncia mais ou menos enfatizada ou acentuada, faz com que a mensagem chegue perfeita ao telespectador. O mal emprego das mesmas desvaloriza uma mensagem e até possibilita o seu mal entendimento, formulando outro sentido ou até modificando-o. (CUNHA, 1990, p. 52)

Deste modo, entendemos que não é mais o tom grave que está em pauta, mas sim o modo de se transmitir a notícia. Kyrillos (2003) explica que, como na televisão existe a presença da imagem, aquele padrão impostado mostrou-se excessivo. Ao perceber isso, o jornalista começou a desenvolver um novo estilo de apresentação que o permitisse entrar na casa das pessoas sendo bem recebido, ao mesmo tempo que transmitia informações e conquistava a confiança de cada uma daquelas pessoas. Assim, ele ganha "pontos" para si mesmo e para o jornal ao mesmo tempo que aumenta a credibilidade do jornal e, consequentemente, da emissora vinculada.

\section{Metodologia}

Com o propósito de responder nossa questão, a lembrar, se há uma relação entre confiabilidade da matéria e a altura de voz do repórter, optamos por fazer um estudo de impressão com o intuito de investigar como as pessoas percebem a voz dos telejornalistas e como avaliam as matérias telejornalísticas. Para isso, aplicamos um teste de percepção a três grupos de estudantes de graduação das áreas de Humanas, Exatas, da Terra e da Saúde (com o propósito de termos um público balanceado).

Com esse teste tínhamos a intenção de investigar a relação entre a forma como o público geral percebia a altura da voz dos jornalistas pesquisados e a confiabilidade das matérias. Para isso, escolhemos notícias que foram exibidas pelo Jornal Nacional, SBT Brasil e Jornal da Record, em 18 de maio de 2017, com o propósito de estabelecermos um 
ponto de comparação (e para não corrermos o risco tendenciosidade) optamos por escolher matérias que apresentavam a mesma temática num mesmo dia de exibição.

Para compor o quadro de juízes, definimos 4 estudantes de cada área para cada um dos três grupos, totalizando 48 juízes: 24 homens e 24 mulheres com idades entre 18 e 33 anos, moradores do estado da Bahia. Nenhum participante relatou problemas de audição e/ou visão.

Tabela 1: Sujeitos selecionados para o teste de percepção.

\begin{tabular}{|l|c|c|c|}
\hline Estudantes: & Grupo 1 (Sujeitos) & Grupo 2 (Sujeitos) & Grupo 3 (Sujeitos) \\
\hline Humanas & 4 & 4 & 4 \\
\hline Naturais e da Terra & 4 & 4 & 4 \\
\hline Saúde & 4 & 4 & 4 \\
\hline Exata & 4 & 4 & 4 \\
\hline Total de sujeitos & $\mathbf{1 6}$ & $\mathbf{1 6}$ & $\mathbf{1 6}$ \\
\hline
\end{tabular}

Fonte: Elaboração própria.

A escolha dos juízes e a separação destes entre os grupos, se deu em função da característica de cada grupo:

- Grupo 1: nesse grupo os juízes assistiam às matérias dos telejornais sabendo previamente a qual telejornal cada notícia pertencia.

- Grupo 2: grupo no qual os juízes ouviam as matérias dos telejornais sem ver as imagens. A esse grupo foi informado sobre a origem de cada matéria.

- Grupo 35: os juízes desse grupo ouviam as matérias dos telejornais sem ver as imagens e sem informação sobre a qual telejornal pertenciam.

Escolhemos utilizar três grupos distintos de informantes, pensando na possibilidade de outros fatores que não o estritamente de interpretação acústica, como questões ideológicas, de gosto e afins, pudessem intervir no teste de percepção. Desse modo, essa metodologia, concorreu para atenuar os efeitos dessas variáveis no resultado. Além disso, os 
juízes foram orientados a observarem apenas as vozes e a qualidade semântica do conteúdo, deixando de lado outras questões que não se relacionassem com os nossos estudos.

Para a aplicação do teste de percepção, utilizamos o laboratório de Pesquisa em Fonética e Fonologia (Lapeff), situado na Universidade Estadual do Sudoeste da Bahia (UESB). Buscando garantir o máximo de silêncio possível, aplicamos os testes em dias em que não havia aula no prédio, ou encontro de pesquisa nos laboratórios vizinhos.

Através do programa Windows Media Player, todas as notícias foram exibidas de maneira aleatória para não corrermos o risco de parcialidade ou tendenciosidade para alguma emissora. Essas matérias foram apresentadas para os juízes assistirem/ouvirem de forma individual ou em grupos de até 4 pessoas. Quando em grupo, os avaliadores se sentavam lado a lado em frente à mesa onde estava o computador portátil e ouviam/assistiam as matérias. Nestes casos, nenhum juiz viu ou soube da resposta do outro.

Cada indivíduo assistiu/ouviu as matérias e ao final de cada uma delas preencheu um questionário com respostas que obedeciam à escala de diferencial semântico correspondente à matéria assistida.

Sousa (2006) explica que a escala de diferencial semântico é um procedimento que utilizamos para "medir" o grau de importância de um determinado assunto para cada indivíduo. Nela, utilizamos uma escala de cinco ou sete pontos que comumente são adjetivos opostos. No nosso caso, por exemplo, pedimos para os juízes avaliarem a altura da voz dos jornalistas e o grau de confiabilidade da notícia. No questionário seguimos a seguinte escala para a avaliação da voz do jornalista: Muito grave - Grave - Mediano - Aguda - Muito aguda. E para a avaliação do grau de confiabilidade: Nenhuma - Pouca - Moderada - Boa - Ótima.

Após a aplicação do teste, fizemos a tabulação dos dados. Para isso, utilizamos uma ferramenta do Google, o Google Formulários, que possibilita a criação de formulários digitais online e mantém uma quantidade de mecanismos que facilitam a análise de dados. Com o auxílio desta ferramenta, copiamos o formulário impresso e em seguida, preenchemos o formulário digital utilizando as respostas dos questionários impressos aplicados e, 
ao final, exportamos os dados agrupados em formato .xlsx, para o software Excel 2016, da suíte Office da Microsoft, para organizarmos os dados.

Já no Excel 2016, utilizamos da fórmula: =CONT.SE('intervalo'; “critérios”) para somar as variáveis e automatizar o trabalho. Essa fórmula conta quais das células selecionadas atendem a um critério. Por exemplo: utilizamos a função =CONT.SE('Jornais Noturnos de 2017'!C3:C18;"Grave") quando queríamos contar quantas vezes a variável "Grave" aparecia entre as células C3 e C18 da planilha "Jornais Noturnos de 2017”. Com isso obtivemos os valores com precisão.

Assim obtivemos as respostas dos juízes, que apresentaremos e discutiremos na próxima seção.

\section{Resultados e discussão}

Conforme apresentamos até aqui, neste trabalho desejamos entender se há uma relação entre a confiabilidade e a altura da voz dos jornalistas. Considerando os pensamentos dos autores supracitados a respeito de confiabilidade e altura de voz, podemos então nos debruçar sobre os dados tabulados do teste de percepção conforme apresentamos a seguir.

Recordemos que os três grupos que compõem esta pesquisa avaliaram tanto a questão da confiabilidade da notícia apresentada pelos telejornais, Jornal Nacional (JN), SBT Brasil (SBTB) e Jornal da Record (JR), quanto à altura da voz de cada jornalista que transmitiu a notícia, José Roberto Burnier, do JN, Daniel Adjuto do SBTB e Cleila Garcia do JR. Assim, analisaremos as duas questões apresentadas aos grupos individualmente.

Ao avaliarmos a questão da confiabilidade da matéria do Jornal Nacional, narrada pelo repórter José Roberto Burnier (Ver tabela 2), verificamos que 69\% dos participantes do grupo 1 , grupo que assistiu à matéria, concordaram que ela passava boa confiança. No grupo 2, grupo que apenas ouviu a matéria sabendo que se tratava do JN, houve maior variação entre as respostas, no entanto, ainda para a maioria, 56\%, a matéria tinha boa confiabilidade. Já no grupo 3, grupo que ouviu a matéria sem saber de qual jornal se tratava, houve menos variação, e nenhum participante achou que a notícia não tinha confiabilidade. Neste grupo, $50 \%$ dos participantes concordaram que a matéria passava boa confiança. 
De modo geral, notamos que a porcentagem daqueles que confiam na notícia do JN é maior que aqueles que não confiam.

Tabela 2: Resultados referentes às respostas dadas à pergunta sobre a confiabilidade da notícia do Jornal Nacional para os grupos avaliados.

\begin{tabular}{c|cc|cc|cc|c}
\hline \multirow{2}{*}{ Opções } & \multicolumn{2}{|c|}{ Grupo 1 } & \multicolumn{2}{c|}{ Grupo 2 } & \multicolumn{2}{c|}{ Grupo 3 } & \multirow{2}{*}{ Total } \\
\cline { 2 - 6 } & \multicolumn{2}{|c|}{ Respostas dadas } & \multicolumn{2}{c|}{ Respostas dadas } & \multicolumn{2}{c|}{ Respostas dadas } & $(\%)$ \\
Nenhuma & $0 / 16$ & $0 \%$ & $1 / 16$ & $7 \%$ & $0 / 16$ & $0 \%$ & 2 \\
Pouca & $2 / 16$ & $12,5 \%$ & $2 / 16$ & $12 \%$ & $0 / 16$ & $0 \%$ & 8 \\
Moderada & $1 / 16$ & $6 \%$ & $2 / 16$ & $12 \%$ & $5 / 16$ & $31 \%$ & 17 \\
Boa & $11 / 16$ & $69 \%$ & $9 / 16$ & $56 \%$ & $8 / 16$ & $50 \%$ & 58 \\
\hline Ótima & $2 / 16$ & $12,5 \%$ & $2 / 16$ & $12 \%$ & $3 / 16$ & $19 \%$ & 15 \\
\hline
\end{tabular}

Fonte: Elaboração própria.

Já ao analisarmos as repostas sobre a altura da voz do repórter, notamos que a voz de Burnier do JN foi percebida pelos juízes do grupo 1 desde "grave” (19\%) até "aguda" (19\%), contudo, a maioria dos juízes avaliaram a voz do jornalista como sendo "mediana" (62\%). No grupo 2 houve uma maior discrepância entre as respostas variando desde o "muito grave" (12\%) até o "aguda" (6\%), contudo, mais uma vez, a maioria dos juízes acharam a voz do repórter "mediana" (44\%). Por fim, no grupo 3, as respostas foram de "grave" (25\%) até o "muito aguda" (6\%), sendo mais uma vez avaliada como "mediana" pela maioria dos juízes (44\%). Apesar da divergência entre as respostas dos juízes e da variabilidade, notamos que de modo geral, os resultados tendem mais do "mediano" para o "grave" do que para o "agudo". O que se é esperado para uma voz masculina. Observemos a tabela 3:

Tabela 3: Resultados referentes às respostas dadas à pergunta sobre a altura da voz do repórter José Roberto Burnier, para os três grupos avaliados.

\begin{tabular}{|c|c|c|c|c|c|c|c|}
\hline \multirow[b]{2}{*}{ Opções } & \multicolumn{2}{|c|}{ Grupo 1} & \multicolumn{2}{|c|}{ Grupo 2} & \multicolumn{2}{|c|}{ Grupo 3} & \multirow{2}{*}{$\begin{array}{c}\text { Total } \\
(\%)\end{array}$} \\
\hline & Respos & ladas & Respo & dadas & Resp & dadas & \\
\hline Muito grave & $0 / 16$ & $0 \%$ & $2 / 16$ & $12 \%$ & $0 / 16$ & $0 \%$ & 4 \\
\hline Grave & $3 / 16$ & $19 \%$ & $6 / 16$ & $38 \%$ & $4 / 16$ & $25 \%$ & 27 \\
\hline Mediana & $10 / 16$ & $62 \%$ & $7 / 16$ & $44 \%$ & $7 / 16$ & $44 \%$ & 50 \\
\hline Aguda & $3 / 16$ & $19 \%$ & $1 / 16$ & $6 \%$ & $4 / 16$ & $25 \%$ & 17 \\
\hline Muito aguda & $0 / 16$ & $0 \%$ & $0 / 16$ & $0 \%$ & $1 / 16$ & $6 \%$ & 2 \\
\hline
\end{tabular}

Fonte: Elaboração própria. 
É importante salientar que a altura é um parâmetro comparativo, ou seja, a voz de um sujeito é percebida como mais grave ou mais aguda em relação a outra voz. (Lembremos que Cagliari (1997, 2007) e Pacheco (2006) afirmam que a voz do homem é mais grave em comparação a voz da mulher). Ainda se faz necessário lembrar que esse parâmetro acústico também está envolto por uma percepção pessoal do que é grave ou agudo e por isso mesmo, que tivermos essas divergências entre as respostas. Por essa razão, apesar de considerar todas as respostas, nos baseamos na avaliação da maioria para considerar qual a altura da voz do jornalista.

Nessa matéria, se considerarmos o percentual de "boa" e "ótima" confiabilidade e contrapor ao percentual de "grave" e "mediana", podemos identificar que talvez haja uma relação entre confiabilidade e altura da voz, já que a maioria dos entrevistados acharam que a matéria passou confiança e que - em sua maioria - a voz do repórter varia de "mediana" a "grave". No entanto, observando as respostas separadamente, notamos que nem sempre o tom grave condiz com uma boa confiabilidade ou que a voz aguda leva à pouca confiabilidade. Vejamos o quadro $1^{6}$.

Quadro 1: Resultados referentes à relação entre confiabilidade da matéria e altura da voz do repórter José Roberto Burnier, para os três grupos avaliados.

\begin{tabular}{c|c|c|c|c|c|c} 
& \multicolumn{2}{|c|}{ Grupo 1 } & \multicolumn{2}{c}{ Grupo 2 } & \multicolumn{2}{c}{ Grupo 3 } \\
\cline { 2 - 6 } Sujeitos & $\begin{array}{c}\text { Confiabili- } \\
\text { dade }\end{array}$ & $\begin{array}{c}\text { Altura da } \\
\text { voz }\end{array}$ & $\begin{array}{c}\text { Confiabili- } \\
\text { dade }\end{array}$ & $\begin{array}{c}\text { Altura da } \\
\text { voz }\end{array}$ & $\begin{array}{c}\text { Confiabili- } \\
\text { dade }\end{array}$ & $\begin{array}{c}\text { Altura da } \\
\text { voz }\end{array}$ \\
\hline Suj. 1 & Pouca & Mediana & Nenhuma & Mediana & Moderada & Grave \\
\hline Suj. 2 & Pouca & Mediana & Pouca & Muito grave & Moderada & Mediana \\
\hline Suj. 3 & Moderada & Mediana & Pouca & Mediana & Moderada & Mediana \\
\hline Suj. 4 & Boa & Grave & Moderada & Grave & Moderada & Mediana \\
\hline Suj. 5 & Boa & Grave & Moderada & Mediana & Moderada & Mediana \\
\hline Suj. 6 & Boa & Mediana & Boa & Muito grave & Boa & Grave \\
\hline Suj. 7 & Boa & Mediana & Boa & Grave & Boa & Grave \\
\hline Suj. 8 & Boa & Mediana & Boa & Grave & Boa & Grave \\
\hline
\end{tabular}

${ }^{6}$ As informações apresentadas nos quadros foram reorganizadas baseadas nas respostas sobre confiabilidade de modo a otimizar a visualização e garantir melhor compreensão dos dados. 


\begin{tabular}{c|c|c|c|c|c|c}
\hline Suj. 9 & Boa & Mediana & Boa & Grave & Boa & Mediana \\
\hline Suj. 10 & Boa & Mediana & Boa & Grave & Boa & Mediana \\
\hline Suj. 11 & Boa & Mediana & Boa & Mediana & Boa & Mediana \\
\hline Suj. 12 & Boa & Aguda & Boa & Mediana & Boa & Aguda \\
\hline Suj. 13 & Boa & Aguda & Boa & Mediana & Boa & Muito aguda \\
\hline Suj. 14 & Boa & Aguda & Boa & Aguda & Ótima & Aguda \\
\hline Suj. 15 & Ótima & Grave & Ótima & Grave & Ótima & Aguda \\
\hline Suj. 16 & Ótima & Mediana & Ótima & Mediana & Ótima & Aguda \\
\hline
\end{tabular}

Fonte: Elaboração própria

Os sujeitos que consideraram a matéria sem "nenhuma" confiabilidade ou que passou "pouca" confiança foram os mesmos que acharam a voz de Burnier "mediana” ou "muito grave". Em contrapartida, os sujeitos que consideraram a confiabilidade como "ótima", perceberam a voz do repórter como "aguda", "mediana" e "grave".

Apesar de serem poucos números $(2 \%$ acreditam que a matéria não tem nenhuma confiabilidade e $8 \%$ acham que tem pouca), eles nos sugerem que a confiabilidade pode não estar relacionada diretamente ao tom de voz "grave”, já que, como vimos, há aceitação da notícia mesmo quando o sujeito percebe a voz do jornalista como "aguda".

Outro ponto que merece atenção é o fato de que os três sujeitos que avaliaram a confiabilidade da notícia como "ótima" e acharam a voz do repórter "aguda" foram os que ouviram a matéria sem saber da sua origem. Ou seja, teoricamente não foram influenciados por nenhuma outra questão que não fosse a altura da voz e a confiança que essa voz transmitiu ao narrar a notícia.

Nessa matéria, o maior nível de incidência recaiu sobre a opção de "boa confiabilidade" - 50\% dos participantes dos três grupos -, nela, houve também a maior variação entre as respostas sobre a altura da voz. Apesar de $25 \%$ dos sujeitos, que afirmam que a matéria é confiável acreditarem que a voz do repórter é “mediana”, houve ainda aqueles que entenderam a voz como "muito aguda" (2,08\%), "aguda" (10,41\%), "grave" (18,75\%) e "muito 
grave" $(2,08 \%)^{7}$. Dessa forma, verificamos a variedade entre as respostas e notamos que a princípio não dá para afirmar que a boa confiabilidade está para uma voz "mediana"e "grave", já que temos respostas que nos informam o contrário.

Em relação a matéria produzida e exibida pelo telejornal SBT Brasil e apresentada pelo repórter Daniel Adjuto, ao analisarmos as respostas dos participantes de cada grupo, notamos que nenhum deles achou que a matéria não passava confiança.

No grupo 1, 19\% dos juízes avaliaram a notícia com "pouca" confiabilidade, já para $25 \%$ dos juízes a matéria era "moderadamente" confiável, $44 \%$ dos sujeitos da pesquisa acreditaram que a matéria tinha "boa" confiabilidade e 12\% acharam a confiabilidade "ótima". No grupo 2, observamos que a porcentagem dos que acharam a matéria "ponco" confiável cai para $12 \%$ e aumenta para $44 \%$ o número daqueles que acharam a matéria "moderadamente" confiável. Ainda há $31 \%$ que acham que a notícia passava "boa" confiança e aqueles que avaliaram a notícia como "ótima" (13\%). No grupo 3, percebemos que para a maioria dos juízes, $50 \%$, a matéria passou "boa" confiança, enquanto para $31 \%$ a notícia foi "moderadamente" confiável. Houve também aqueles que acharam que a matéria era "pouco" confiável $(13 \%)$ e aqueles que avaliaram a confiabilidade como "ótima" (6\%). Observemos a tabela 4:

Tabela 4: Resultados referentes às respostas dadas à pergunta sobre a confiabilidade da notícia do SBT Brasil para os grupos avaliados.

\begin{tabular}{c|cc|cc|cc|c}
\hline \multirow{2}{*}{ Opções } & \multicolumn{2}{|c|}{ Grupo 1 } & \multicolumn{2}{c|}{ Grupo 2 } & \multicolumn{2}{c|}{ Grupo 3 } & Total \\
\cline { 2 - 6 } & \multicolumn{2}{|c|}{ Respostas dadas } & \multicolumn{2}{c|}{ Respostas dadas } & \multicolumn{2}{c|}{ Respostas dadas } \\
Nenhuma & $0 / 16$ & $0 \%$ & $0 / 16$ & $0 \%$ & $0 / 16$ & $0 \%$ & 0 \\
Pouca & $3 / 16$ & $19 \%$ & $2 / 16$ & $12 \%$ & $2 / 16$ & $13 \%$ & 15 \\
Moderada & $4 / 16$ & $25 \%$ & $7 / 16$ & $44 \%$ & $5 / 16$ & $31 \%$ & 33 \\
Boa & $7 / 16$ & $44 \%$ & $5 / 16$ & $31 \%$ & $8 / 16$ & $50 \%$ & 42 \\
\hline Ótima & $2 / 16$ & $12 \%$ & $2 / 16$ & $13 \%$ & $1 / 16$ & $6 \%$ & 10 \\
\hline
\end{tabular}

Fonte: Elaboração própria.

\footnotetext{
${ }^{7}$ Resultados obtidos a partir do cálculo de percentual do total de cada opção de altura de voz em função do total de cada opção de confiabilidade.
} 
Já em relação a voz do jornalista, $6 \%$ dos sujeitos do grupo 2 acharam que a voz era "muito grave", 19\% dos participantes dos três grupos acharam a voz do repórter "grave", 75\% dos entrevistados dos três grupos afirmaram que o repórter tinha a voz "mediana", $6 \%$ das pessoas do grupo 1 e 3 acharam que a voz do repórter era "aguda", conforme se observa na tabela 5. De modo geral, há uma tendência a acreditar que a voz de Daniel Adjuto varia entre o tom "mediano" e o "grave".

Tabela 5: Resultados referentes às respostas dadas à pergunta sobre a altura da vOz do repórter Daniel Adjuto, para os três grupos avaliados.

\begin{tabular}{c|cc|cc|cc|c}
\hline & \multicolumn{2}{|c|}{ Grupo 1 } & \multicolumn{2}{c|}{ Grupo 2 } & \multicolumn{2}{c|}{ Grupo 3 } & Total \\
\cline { 2 - 6 } Opções & \multicolumn{2}{|c|}{ Respostas dadas } & \multicolumn{2}{c|}{ Respostas dadas } & \multicolumn{2}{c|}{ Respostas dadas } & (\%) \\
Muito grave & $0 / 16$ & $0 \%$ & $1 / 16$ & $6 \%$ & $0 / 16$ & $0 \%$ & 2 \\
Grave & $3 / 16$ & $19 \%$ & $3 / 16$ & $19 \%$ & $3 / 16$ & $19 \%$ & 19 \\
Mediana & $12 / 16$ & $75 \%$ & $12 / 16$ & $75 \%$ & $12 / 16$ & $75 \%$ & 75 \\
Aguda & $1 / 16$ & $6 \%$ & $0 / 16$ & $0 \%$ & $1 / 16$ & $6 \%$ & 4 \\
Muito aguda & $0 / 16$ & $0 \%$ & $0 / 16$ & $0 \%$ & $0 / 16$ & $0 \%$ & 0 \\
\hline
\end{tabular}

Fonte: Elaboração própria.

Se considerarmos essas primeiras respostas gerais sobre a confiabilidade da matéria e a altura da voz do jornalista, mais uma vez notamos que pode haver uma relação entre o tom mais grave e a confiabilidade, já que novamente a maioria dos participantes avaliaram a voz do repórter como "mediana" ou "grave" e também consideraram que a notícia é confiável.

No entanto, ao observarmos as respostas separadamente no quadro 2, constatamos que todos os sujeitos que responderam que a matéria passou "pouca" confiança também responderam que a voz do repórter era "mediana", da mesma forma que $65 \%{ }^{8}$ dos sujeitos que acharam que a matéria teve "boa" confiança também responderam que a voz de Adjuto era "mediana". Apenas 30\% dos juízes que responderam que a matéria tinha "boa" confiabilidade acharam a voz do repórter "grave". Houve ainda 1 caso (5\%) em que a pessoa achou

${ }^{8}$ Resultados obtidos a partir do cálculo de percentual do total de cada opção de altura de voz em função do total de cada opção de confiabilidade. 
a voz do jornalista "aguda", mas ainda assim considerou a confiabilidade da matéria como "boa".

75\% dos sujeitos que consideraram a notícia de "moderada" confiabilidade também acharam voz de Adjuto "mediana", enquanto 12\% acharam "grave", 6,25\% acharam ou "aguda" ou "muito grave". Por fim, daqueles que acharam que a matéria era "muito" confiável, $80 \%$ avaliaram a vOz do repórter "mediana" e apenas $20 \%$ acharam que era "grave". Notemos o quadro 2:

Quadro 2: Resultados referentes à relação entre confiabilidade da matéria e altura da voz do repórter Daniel Adjuto, para os três grupos avaliados.

\begin{tabular}{c|c|c|c|c|c|c}
\hline \multirow{2}{*}{$\begin{array}{c}\text { Sujei- } \\
\text { tos }\end{array}$} & \multicolumn{2}{|c|}{ Grupo 1 } & \multicolumn{2}{c}{ Grupo 2 } & \multicolumn{2}{c}{ Grupo 3 } \\
\cline { 2 - 7 } & $\begin{array}{c}\text { Confiabili- } \\
\text { dade }\end{array}$ & $\begin{array}{c}\text { Altura da } \\
\text { voz }\end{array}$ & $\begin{array}{c}\text { Confiabili- } \\
\text { dade }\end{array}$ & $\begin{array}{c}\text { Altura da } \\
\text { voz }\end{array}$ & $\begin{array}{c}\text { Confiabili- } \\
\text { dade }\end{array}$ & $\begin{array}{c}\text { Altura da } \\
\text { voz }\end{array}$ \\
\hline Suj. 1 & Pouca & Mediana & Pouca & Mediana & Pouca & Mediana \\
\hline Suj. 2 & Pouca & Mediana & Pouca & Mediana & Pouca & Mediana \\
\hline Suj. 3 & Pouca & Mediana & Moderada & Muito grave & Moderada & Grave \\
\hline Suj. 4 & Moderada & Grave & Moderada & Mediana & Moderada & Mediana \\
\hline Suj. 5 & Moderada & Mediana & Moderada & Mediana & Moderada & Mediana \\
\hline Suj. 6 & Moderada & Mediana & Moderada & Mediana & Moderada & Mediana \\
\hline Suj. 7 & Moderada & Mediana & Moderada & Mediana & Moderada & Aguda \\
\hline Suj. 8 & Boa & Grave & Moderada & Mediana & Boa & Grave \\
\hline Suj. 9 & Boa & Grave & Moderada & Mediana & Boa & Grave \\
\hline Suj. 10 & Boa & Mediana & Boa & Grave & Boa & Mediana \\
\hline Suj. 11 & Boa & Mediana & Boa & Grave & Boa & Mediana \\
\hline Suj. 12 & Boa & Mediana & Boa & Mediana & Boa & Mediana \\
\hline Suj. 13 & Boa & Mediana & Boa & Mediana & Boa & Mediana \\
\hline Suj. 14 & Boa & Aguda & Boa & Mediana & Boa & Mediana \\
\hline Suj. 15 & Ótima & Mediana & Ótima & Grave & Boa & Mediana \\
\hline Suj. 16 & Ótima & Mediana & Ótima & Mediana & Ótima & Mediana \\
\hline
\end{tabular}

Fonte: Elaboração própria.

Esses casos, assim como os da primeira matéria, levantam dúvidas acerca da hipótese de que a confiabilidade e a voz grave estão diretamente relacionadas. Contudo, os resultados também não se apresentam como fatores que determinam uma total desvinculação entre a confiabilidade e a voz grave. Apesar de a maioria ainda apontar para a relação de uma com a outra, as exceções nos impedem de afirmar isso categoricamente ou, ainda, de visualizar um padrão claro, já que, nesse caso, o que seria esperado como pouca 
confiabilidade para a voz aguda e muita confiabilidade para a voz grave, no caso de jornalistas homens, conforme indicam Panico e Fukusima (2003) e Batista e Figueiredo (2010), não se estabelece.

Por fim, na matéria do Jornal da Record, noticiado por Cleisla Garcia, tivemos os seguintes resultados: para 6\% dos sujeitos do grupo 1 e $12 \%$ do grupo 3 , a notícia teve "pouca" confiabilidade. Para 19\% dos participantes do grupo 1, 19\% do grupo 2 e 13\% do grupo 3, a matéria teve "moderada" confiabilidade. Já para $62 \%$ dos entrevistados do grupo 1, $62 \%$ do grupo 2 e $69 \%$ do grupo 3, a notícia teve "boa" confiabilidade e para $13 \%$ do grupo 1, 19\% do grupo 2 e $6 \%$ do grupo 3 a matéria se apresentou "muito" confiável. Vejamos na tabela 6 :

Tabela 6: Resultados referentes às respostas dadas à pergunta sobre a confiabilidade da notícia do Jornal da Record para os grupos avaliados.

\begin{tabular}{c|cc|cc|cc|c}
\hline \multirow{2}{*}{ Opções } & \multicolumn{2}{|c|}{ Grupo 1 } & \multicolumn{2}{c|}{ Grupo 2 } & \multicolumn{2}{c|}{ Grupo 3 } & Total \\
\cline { 2 - 6 } & \multicolumn{2}{|c|}{ Respostas dadas } & \multicolumn{2}{c|}{ Respostas dadas } & \multicolumn{2}{c|}{ Respostas dadas } & (\%) \\
Nenhuma & $0 / 16$ & $0 \%$ & $0 / 16$ & $0 \%$ & $0 / 16$ & $0 \%$ & $0 \%$ \\
Pouca & $1 / 16$ & $6 \%$ & $0 / 16$ & $0 \%$ & $2 / 16$ & $12 \%$ & $6 \%$ \\
Moderada & $3 / 16$ & $19 \%$ & $3 / 16$ & $19 \%$ & $2 / 16$ & $13 \%$ & $17 \%$ \\
Boa & $10 / 16$ & $62 \%$ & $10 / 16$ & $62 \%$ & $11 / 16$ & $69 \%$ & $65 \%$ \\
\hline Ótima & $2 / 16$ & $13 \%$ & $3 / 16$ & $19 \%$ & $1 / 16$ & $6 \%$ & $13 \%$ \\
\hline
\end{tabular}

Fonte: Elaboração própria.

Assim como as duas matérias anteriores, apesar da variação das respostas, é perceptível que as matérias são percebidas como confiáveis pela maioria dos telespectadores.

Em relação as respostas sobre a altura da voz da repórter Cleisla Garcia, do Jornal da Record, as respostas variaram de "grave" à "aguda". Observamos que nenhum juiz avaliou a voz da jornalista como "muito grave", nem como "muito aguda". $6 \%$ dos juízes do grupo 1 , $12 \%$ do grupo 2 e 13\% do grupo 3 acharam a voz de Garcia "grave". Já para 63\% dos juízes do grupo 1,75\% do grupo 2 e 56\% do grupo 3 avaliaram a voz da repórter como "mediana" e para $31 \%$ dos sujeitos do grupo 1, 13\% do grupo 2 e 31\% do grupo 3, a voz foi interpretada como "aguda", de acordo com o que se vê na tabela 7 . 
Tabela 7: Resultados referentes às respostas dadas à pergunta sobre a altura da voz do repórter Cleisla Garcia, para os três grupos avaliados.

\begin{tabular}{c|cc|cc|cc|c}
\hline & \multicolumn{2}{|c|}{ Grupo 1 } & \multicolumn{2}{c|}{ Grupo 2 } & \multicolumn{2}{c|}{ Grupo 3 } & Total \\
\cline { 2 - 6 } Opções & \multicolumn{2}{|c|}{ Respostas dadas } & \multicolumn{2}{c|}{ Respostas dadas } & \multicolumn{2}{c|}{ Respostas dadas } & (\%) \\
Muito grave & $0 / 16$ & $0 \%$ & $0 / 16$ & $0 \%$ & $0 / 16$ & $0 \%$ & 0 \\
Grave & $1 / 16$ & $6 \%$ & $2 / 16$ & $12 \%$ & $2 / 16$ & $13 \%$ & 10 \\
Mediana & $10 / 16$ & $63 \%$ & $12 / 16$ & $75 \%$ & $9 / 16$ & $56 \%$ & 65 \\
Aguda & $5 / 16$ & $31 \%$ & $2 / 16$ & $13 \%$ & $5 / 16$ & $31 \%$ & 25 \\
Muito aguda & $0 / 16$ & $0 \%$ & $0 / 16$ & $0 \%$ & $0 / 16$ & $0 \%$ & 0 \\
\hline
\end{tabular}

Fonte: Elaboração própria.

Nesse exemplo, nós temos alguns fenômenos interessantes. Primeiro, diferente das outras duas matérias, essa é noticiada por uma mulher. Segundo que, por ser mulher, comumente é de se esperar uma voz mais aguda, mas a maioria dos juízes - 65\% - identificaram a voz como "mediana", isso indica que a voz de Cleisla Garcia não é considerada aguda, mas também não é grave. Ao mesmo tempo, a matéria foi avaliada como apresentando "boa" confiabilidade, também pela maioria - 65\% - dos participantes de modo geral.

Ao compararmos as respostas individualmente (observemos o quadro 3, a seguir), notamos que os juízes que caracterizaram a matéria como "pouco" confiável se dividiram entre achar o tom da voz da repórter "agudo", "mediano" e "grave”. Dentre os que apontaram que a matéria tenha passado "moderada" confiança, 62,5\%9 acharam a voz de Garcia "mediana", enquanto $25 \%$ acharam "grave" e apenas $12,5 \%$ consideraram "aguda".

Dos juízes que acharam a confiabilidade "boa", 70,96\% consideraram a voz da repórter "mediana", ao passo que 25,8\% deles acharam a voz "aguda" e apenas 3,22\% avaliaram a voz como "grave". Alternativamente, para os participantes que classificaram a matéria como de "ótima" confiança, 50\% perceberam a voz da repórter como "mediana", 33,3\% acharam a voz "aguda" e apenas 16,6\% a consideraram "grave”.

${ }^{9}$ Resultados obtidos a partir do cálculo de percentual do total de cada opção de altura de voz em função do total de cada opção de confiabilidade. 
Quadro 3: Relação entre confiabilidade da matéria e altura da voz da repórter Cleisla Garcia.

\begin{tabular}{|c|c|c|c|c|c|c|}
\hline \multirow{2}{*}{$\begin{array}{l}\text { Sujeitos } \\
\text { Suj. } 1 \\
\end{array}$} & \multicolumn{2}{|c|}{$\begin{array}{c}\text { Confiabilidade/Altura da } \\
\text { voz - Grupo } 1\end{array}$} & \multicolumn{2}{|c|}{$\begin{array}{c}\text { Confiabilidade/Altura da } \\
\text { voz -Grupo } 2\end{array}$} & \multicolumn{2}{|c|}{$\begin{array}{c}\text { Confiabilidade/Altura } \\
\text { da voz -Grupo } 3\end{array}$} \\
\hline & Pouca & Mediana & Moderada & Grave & Pouca & Grave \\
\hline Suj. 2 & Moderada & Mediana & Moderada & Mediana & Pouca & Aguda \\
\hline Suj. 3 & Moderada & Mediana & Moderada & Mediana & Moderada & Grave \\
\hline Suj. 4 & Moderada & Aguda & Boa & Grave & Moderada & Mediana \\
\hline Suj. 5 & Boa & Mediana & Boa & Mediana & Boa & Mediana \\
\hline Suj. 6 & Boa & Mediana & Boa & Mediana & Boa & Mediana \\
\hline Suj. 7 & Boa & Mediana & Boa & Mediana & Boa & Mediana \\
\hline Suj. 8 & Boa & Mediana & Boa & Mediana & Boa & Mediana \\
\hline Suj. 9 & Boa & Mediana & Boa & Mediana & Boa & Mediana \\
\hline Suj. 10 & Boa & Mediana & Boa & Mediana & Boa & Mediana \\
\hline Suj. 11 & Boa & Aguda & Boa & Mediana & Boa & Mediana \\
\hline Suj. 12 & Boa & Aguda & Boa & Mediana & Boa & Mediana \\
\hline Suj. 13 & Boa & Aguda & Boa & Aguda & Boa & Aguda \\
\hline Suj. 14 & Boa & Aguda & Ótima & Mediana & Boa & Aguda \\
\hline Suj. 15 & Ótima & Grave & Ótima & Mediana & Boa & Aguda \\
\hline Suj. 16 & Ótima & Mediana & Ótima & Aguda & Ótima & Aguda \\
\hline
\end{tabular}

Fonte: Elaboração própria.

Mais uma vez, assim como as duas matérias anteriores, verificamos que não existe uma relação direta entre a confiabilidade e a altura da voz, visto que o que ficou proeminente nessas análises foi que nem sempre o juiz que avaliou a matéria como confiável entendeu o tom da voz como grave, tal como nem sempre aquele que avaliou como pouco confiável percebeu o tom como mais agudo.

O que notamos é que, tanto para a voz feminina, quanto para a masculina, houve uma maior incidência nas respostas que caracterizavam a voz como "mediana", assim como maior ocorrência em considerar a matéria como confiável.

Russi (2016, p.92-93) baseada em Herreros (1998) explica que,

a vOZ da locução das notícias não pode ser monótona, nem acelerada, nem excessivamente lenta, o ideal é que a narração seja feita com uma locução natural, simples, equilibrada, ou seja, nem muito grave ou aguda e nem de fraca ou alta intensidade.

Se observarmos as respostas, em especial as que julgam a voz dos repórteres como "mediana”, constatamos que, com exceção da matéria do SBT Brasil, há uma tendência em julgar a informação como confiável. 


\title{
Considerações finais
}

Por meio das discussões dos resultados desta pesquisa, podemos entender, até então, que não existe uma relação intrínseca entre a questão da confiabilidade e a altura de voz, o que, de certo modo, ratifica nossa hipótese, já que não há um padrão entre o achar uma voz grave e a notícia confiável, ou perceber uma voz como aguda e achar a notícia não confiável.

Os resultados apontam que, talvez, as vozes que passem mais confiança sejam justamente aquelas que fiquem no intermédio entre o grave e o agudo, como propõe Herreros (1998 apud RUSSI, 2016) já que os resultados mostram que houve uma maior tendência em julgar como confiável as vozes medianas - apesar de ainda haver respostas contrárias, assim como para os tons graves e agudos.

Levando em conta as informações anteriores sobre a evolução do telejornalismo que saiu de uma voz impostada para uma voz que tenta ser convidada para tomar um café na sala do telespectador -, parece natural que os telejornalistas que tenham uma voz mediana também apresentem maior confiabilidade. Ora, o jornalista agora é gente como a gente. Por que não confiar no que ele está dizendo aí na TV? Esses pensamentos nos fazem levantar uma outra hipótese de que as pessoas tendam a confiar mais naquilo que lhe pareça comum, natural, familiar e por isso mesmo, o telejornalismo venha se modificando ao longo do tempo.

\section{RELATIONSHIP BETWEEN NEWS RELIABILITY AND VOICE HEIGHT OF REPORTERS FROM JN, SBT BRASIL AND JR}

\begin{abstract}
This research raises the following question: is there a relationship between the reliability of the journalistic story and the voice height of reporters? Our hypothesis is that there is no longer an intrinsic relationship between the height of the voice and the reliability of the matter. Our objective, then, is to investigate whether the reliability of a story is related to the height of the television journalist's voice. To do this, we selected videos of news stories broadcast in 2017 and displayed them to a target audience to judge the reliability of the stories and the height of the reporters' voices. The results found confirm our hypothesis that there is no intrinsic relationship between pitch and reliability.
\end{abstract}

KEYWORDS: Reliability; Voice height; Reporters; Television news; Public. 


\section{REFERÊNCIAS}

BATISTA, C. L. C. \& FIGUEIREDO, M. A. V. Telejornalismo e Fonoaudiologia: Reflexões sobre utilização saudável da fonoarticulação. (p. 11) Trabalho apresentado ao Intercom Junior, na Divisão Temática de Jornalismo, do XI Congresso de Ciências da Comunicação na Região Nordeste. Teresina - 14 a 16 de maio de 2009. Disponível em: < http://www.intercom.org.br/papers/regionais/nordeste2009/resumos/R15-0118-1.pdf > Acesso em: 15 Dez. 2017.

BELDA, F. R \& SANTOS, G. S. A concepção e a percepção da credibilidade no jornalismo. Revista Anagrama: Revista Científica Interdisciplinar da Graduação, v. 1, p. 1-16. Disponível em: < https://www.revistas.usp.br/anagrama/article/view/135299/131159 > Acesso em 16 Dez. 2017.

CAGLIARI, L. C. Elementos de fonética do português brasileiro. São Paulo: Paulistana, 2007.

CUNHA, A. A. Telejornalismo. São Paulo: Editora Atlas, 1990.

HERREROS, M. C. Información Televisiva: mediaciones, contenidos, expresión y programación. Madrid: Editorial Síntesis, 1998.

KYRILLOS, L.; COTES, C.; FEIJÓ, D. Voz e corpo na TV : a fonoaudiologia a serviço da comunicação. São Paulo: Globo, 2003.

LEWICKI, R. J. \& TOMLINSON, E. C. Trust and Trust Building. Beyond Intractability. Eds. Guy Burgess and Heidi Burgess. Conflict Information Consortium,

University of Colorado, Boulder. Posted: December, 2003. Disponível em: < http://www.beyondintractability.org/essay/trust-building > . Acessado em 16 Dez. 2017.

MALMBERG, B. A fonética - no mundo dos sons da linguagem. Portugal: Livros do Brasil, 1954.

PACHECO, V. (2006). O efeito dos estímulos auditivo e visual na percep̧ão de marcadores prosódicos lexicais e gráficos usados na escrita do Português do Brasil. 2006. 319 f. Tese (doutorado em Linguística) - Universidade Estadual de Campinas, Campinas, SP, 2006.

PANICO, A. C. B. \& FUKUSIMA, S. S. Confiabilidade - Traços acústicos que a caracterizam e como desenvolvê-los. In: Kyrillos, L. R. (Org.). Fonoaudiologia e Telejornalismo: relatos de experiências na Rede Globo de Televisão. Rio de Janeiro: Revinter, 2003. P. 47-58

PORTINHA, S. A voz das emoções no jornalismo de televisão. In: Actas das Jornadas - $A$

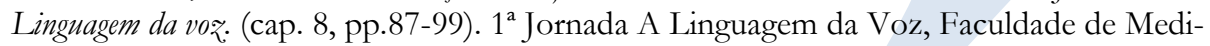
cina de Lisboa. 2011. Disponível em::< https://www.academia.edu/4914421/Atas_das_1as_Jornadas_A_Linguagem_da_Voz_Faculdade_de_Medicina_Universidade_de_Lisboa> Acesso em: 15 Dez 2017.

REINIGER, A. M. História da fonoaudiologia no telejornalismo. In: Kyrillos, L. e FEIJÓ, D. Fonoaudiologia e Telejornalismo. Editora Revinter, Rio de Janeiro, 2004. P. 1-3 
RUSSI, A. C. Voz e telejornalismo: um estudo sobre a construção vocal da credibilidade. $2016.139 \mathrm{f}$. Dissertação (mestrado em Jornalismo - Universidade Federal de Santa Catarina, Florianópolis, SC, 2016. Disponível: < https://repositorio.ufsc.br/handle/123456789/169222> Acesso em: 15, Dezembro, 2017.

SENESE, S.M.M. Stress e desempenho profissional em Telejornalismo.2008 Dissertação (mestrado em Psicologia) - Universidade de São Paulo, São Paulo, SP, 2008. Disponível em: < https://teses.usp.br/teses/disponiveis/47/47134/tde-26052008-142247/publico/Senese_mestrado.pdf > Acesso em 16 Dez. 2017.

SERRA, P. O princípio da credibilidade na seleção da informação mediática. Disponível em: < http://www.bocc.ubi.pt/pag/serra-paulo\%20-credibilidade-seleccao-informacao.pdf.> Acessado em 16 Dez. 2017.

VIGIL, J. I. L. Manual urgente para radialistas apaixonados. São Paulo: Paulinas - Catálogo Geral, 1997.

Recebido em: 23/07/2020.

Aprovado em: 30/12/2020. 